\title{
MANAJEMEN TEKNIK OLAH KAYU KONSTRUKSI DENGAN POTENSI EKONOMI UNTUK PENDAPATAN PETANI HUTAN
}

\author{
Noni Paisah dan Dinda Dewi Aisyah \\ Fakultas Teknik Sipil, Universitas Graha Nusantara, Padang Sidimpuan. 22721 \\ Jurusan Ekonomi Pertanian, Pascasarjana Fakultas Pertanian, Universitas Gajah Mada \\ Yogyakarta. 55281 \\ Email: dinda.dewi.a@mail.ugm.ac.id
}

\begin{abstract}
This study aims to analyze the management of construction wood processing techniques with economic potential for the income offorest farmer. The research location is in Siais Subdistrict, South Tapanuli District, North Sumatra Province. The research method is descriptive survey with primary and secondary data. The results showed that the management of construction wood processing techniques was still simple and traditionally carried out by respondent. This condition results in physical damage vulnerability in processed wood. Respondent often experience losses due to a decrease in the price of processed wood if the construction is damaged
\end{abstract}

Keywords: management, engineering of wood construction, income, forest farmer

\section{PENDAHULUAN}

Petani hutan memiliki pola nafkah ganda untuk menambah alternatif sumber pendapatan. Selain mengerjakan usahatani tanaman pangan, petani hutan juga telah mengusahakan budidaya kayu pada kebun dan berperan menjadi pengelola bisnis skala kecil/menengah olah kayu konstruksi. Pekerjaan olah kayu konstruksi sudah dilakukan selama bertahun-tahun oleh petani hutan wilayah Kecamatan Siais, Kabupaten Tapanuli Selatan, Provinsi Sumatera Utara. Meski demikian, petani hutan tersebut belum melakukan penggunaan teknologi olah kayu konstruksi yang meningkatkan mutu baik dari sisi tekstur dan keawetan.
Potensi ekonomi kayu memiliki beberapa nilai keunggulan sebagai bahan material konstruksi. Kayu sejak dulu menjadi salah satu pilihan sebagai bahan material konstruksi karena kadar emisi CO2 rendah hingga mendukung kelestarian lingkungan hidup khususnya menghadapi ancaman pemanasan global (Dewobroto, 2012). Kayu olah konstruksi termasuk dari sebagian sumberdaya alam yang dapat diperbaharui.

Petani hutan bekerja mengolah kayu untuk bahan material konstruksi secara sederhana dan tradisional. Oleh karena itu, kerusakan kayu mudah terjadi. Harga kayu yang mengalami kerusakan fisik turun sehingga merugikan petani hutan. Kayu yang rusak dibiarkan petani menumpuk dan menjadi beban lingkungan. Tumpukan kayu 
rusak/busuk sebagian dimanfaatkan untuk kepentingan kayu bakar oleh masyarakat sekitar. Sebagian lain tetap tertumpuk dan menjadi sampah yang rentan mengotori lingkungan.

Kerusakan kayu konstruksi dapat dihindari melalui penggunaan beberapa teknologi. Beberapa teknologi tersebut telah dikemukakan oleh para ahli yaitu melalui proses pengaturan kebasahan ketika pemberian lapisan pernis pada permukaan kayu cepat tumbuh Sengon dan Jabon (Darmawan, et al., 2018a). Teknologi lain yang dengan mengatur penataan letak penyimpanan kayu olah konstruksi dalam gudang agar tidak tertumpuk di luar ruang yang lembab. Pengaturan pemotongan atau penggergajian permukaan dengan tingkat kekasaran tertentu juga dapat meningkatkan mutu dari kayu Pinus sehingga memiliki keawetan (Darmawan, et al., 2018b). Peningkatan resistensi kayu terhadap rayap agar tidak mengalami pembusukan dapat juga dilakukan dengan teknik aturan lapisan pengecatan permukaan dan penmberian pengawet Entiblu dan Enborer (Darmawan, et al., 2018c).

Kayu memiliki sifat yang sangat kompleks. Sifat fisik dan kimia kayu tidak dimiliki oleh bahan konstruksi lain. Oleh karena itu, kayu merupakan salah satu sumberdaya alam yang dapat dimanfaatkan secara optimal untuk kepentingan ekonomi, sosial dan budaya dalam memenuhi kebutuhan manusia (Fahrizal dan Muin, 2016). Produksi kayu olah konstruksi memerlukan sistem manajemen yang strategis (Ananta, et al., 2007; Dumasari and Rahayu, 2016). Sistem manajemen strategis yang dimaksud termasuk perilaku petani hutan perlu melakukan identifikasi masalah dan berbagai kebutuhan teknologi disertai pengendalian kontrol usaha kayu olah konstruksi agar terhindar dari risiko kerugian.

Bertolak dari permasalahan petani hutan yang kompleks tersebut mendorong tema penelitian diorientasikan pada analisis manajemen teknik olah kayu konstrksi dengan potensi ekonomi untuk pendapatan petani hutan di Kecamatan Siais, Kabupaten Tapanuli Selatan, Provinsi Sumatera Utara. Topik yang demikian penting dianalisis agar diketahui kondisi permasalahan yang terjadi di lokasi penelitian dan kemudian dilakukan penelitian lanjutan dalam rangka menemukan alternatif penyelesaian masalah. Tujuan penelitian untuk menganalisis teknik olah kayu konstruksi dengan potensi ekonomi untuk pendapatan petani hutan.

\section{METODE PENELITIAN}

Metode penelitian ini ialah kajian lapangan survai yang bersifat deskriptif. Lokasi penelitian dilakukan di Kecamatan Siais, Kabupaten Tapanuli Selatan, Provinsi 
Sumatera Utara. Du wilayah ini terdapat kelompok petani tanaman pangan yang juga melakukan pekerjaan sebagai pekebun dan produsen berbagai jenis kayu olah konstruksi

Data penelitian bersifat primer dan sekunder. Data primer langsung didapat dari responden dan informan kunci. Data sekunder dikumpulkan dari literatur yang ada hubungan dengan tema penelitian. Sumber data sekunder lain berasal dari laporan atau catatan dan dokumen yang memuat materi pendukung bahasan.

Populasi penelitian terdiri dari jumlah keseluruhan petani hutan yang mengelola usaha bisnis olah kayu kondstruksi di lingkungan Kecamatan Siais, Kabupaten Tapanuli Selatan, Provinsi Sumatera Utara. Sumber data primer yakni responden dipilih dengan teknik simple random sampling. Informan kunci ditentukan dengan teknik purposive sampling. Para informan kunci terdiri dari tokoh masyarakat dan aparat desa/kecamatan yang mengerti tentang informasi kayu olah konstruksi yang dikelola oleh petani responden.

Data primer dikumpul dengan wawancara dan pengamatan. Data sekunder ditelusur dengan teknik analisis dokumentasi. Data yang terkumpul lalu diolah dan dianalisis dengan statistik non parametrik (nilai persentase, nilai rerata, tabulasi dan distribusi frekuensi).

\section{HASIL DAN PEMBAHASAN}

Manajemen teknik olah kayu konstruksi yang dilakukan oleh responden masih sederhana dan tradisional dan belum menggunakan teknologi tertentu. Pada saat proses pemotongan/pembelahan kayu dilakukan dengan mesin gergaji potong dan mesin belah kayu. Pada proses ini responden melakukan tanpa memperhatikan kepentingan keawetan kayu. Pemotongan dan pembelahan kayu glondongan dilakukan sesuai kebiasaan dengan memperhatikan ukuran panjang dan ketebalan kayu olah konstruksi.

Semua responden melakukan proses pengawetan bersifat alami. Teknik pengawetan terhadap jenis kayu kapur, meranti, kamper, albazia dan sengon dilakukan dengan proses penjemuran. Lama penjemuran tidak menentu. Penjemuran dilakukan dengan mendirikan kayu secara berjejer di halaman gudang sebelum disimpan secara bertumpuk. Pada beberapa responden, kayu kelapa diawetkan dengan cara merendam pada bak atau kolam perendaman yang disiapkan selama satu-tiga bulan.

Penyimpanan kayu tidak hanya dijejer atau ditumpuk dalam gudang, Akan tetapi, ada juga sebagian yang ditaruh di halaman 
depan, samping dan belakang gudang. Kayu olah konstruksi yang disimpan di luar ditata letak dengan teknik tumpuk dan jejer berlapis. Pada Tabel 1 tertera penjelasan mengenai manajemen teknik olah kayu konstruksi yang selama ini dilakukan oleh responden.

Tabel 1. Manajemen Teknik Olah Kayu Konstruksi oleh Responden

\begin{tabular}{|c|l|c|c|c|c|c|c|}
\hline No. & \multirow{2}{*}{\begin{tabular}{l} 
Jenis Kayu \\
\cline { 3 - 8 }
\end{tabular}} & Konstruksi & \multicolumn{6}{|c|}{ Teknik Olah Mutu } \\
\cline { 3 - 8 } & & Pemotongan/Pembelahan & \multicolumn{2}{|c|}{ Pengawetan } & \multicolumn{2}{c|}{ Penyimpanan } \\
\cline { 3 - 8 } & & Kayu Bulat & $\begin{array}{c}\text { Kayu } \\
\text { Belah }\end{array}$ & Jemur & Rendam & Berjejer & Tertumpuk \\
\hline 1 & Sengon & $\sqrt{ }$ & $\sqrt{ }$ & $\sqrt{ }$ & & $\sqrt{ }$ & $\sqrt{ }$ \\
\hline 2 & Kapur & $\sqrt{ }$ & $\sqrt{ }$ & $\sqrt{ }$ & & $\sqrt{ }$ & $\sqrt{ }$ \\
\hline 3 & Meranti & $\sqrt{ }$ & $\sqrt{ }$ & $\sqrt{ }$ & & $\sqrt{ }$ & $\sqrt{ }$ \\
\hline 4 & Kelapa & $\sqrt{ }$ & $\sqrt{ }$ & & $\sqrt{ }$ & $\sqrt{ }$ \\
\hline 5. & Albazia & $\sqrt{ }$ & $\sqrt{ }$ & $\sqrt{ }$ & & $\sqrt{ }$ & $\sqrt{ }$ \\
\hline 6. & Kamper & $\sqrt{ }$ & $\sqrt{ }$ & $\sqrt{ }$ & & $\sqrt{ }$ & \\
\hline
\end{tabular}

Dengan teknik olah kayu konstruksi yang tertera pada Tabel 1 maka risiko kerusakan sulit dihindari oleh responden. Dalam beberapa selang waktu yang relatif tidak lama, beberapa jenis kayu yang bertekstur lebih lunak segera mengalami kerusakan fisik. Kerusakan lebih cepat disebabkan serangan hama rayap. Kayu albazia dan sengon serta kapur paling rawan mengalami kerusakan fisik dibanding jenis kayu lain. Kerusakan rawan terjadi terutama saat musim hujan. Kondisi kayu rusak tentu menimbulkan kerugian ekonomi bagi responden. Pada Gambar 1 terurai tingkat kerusakan kayu olah konstruksi yang diperdagangkan oleh responden.

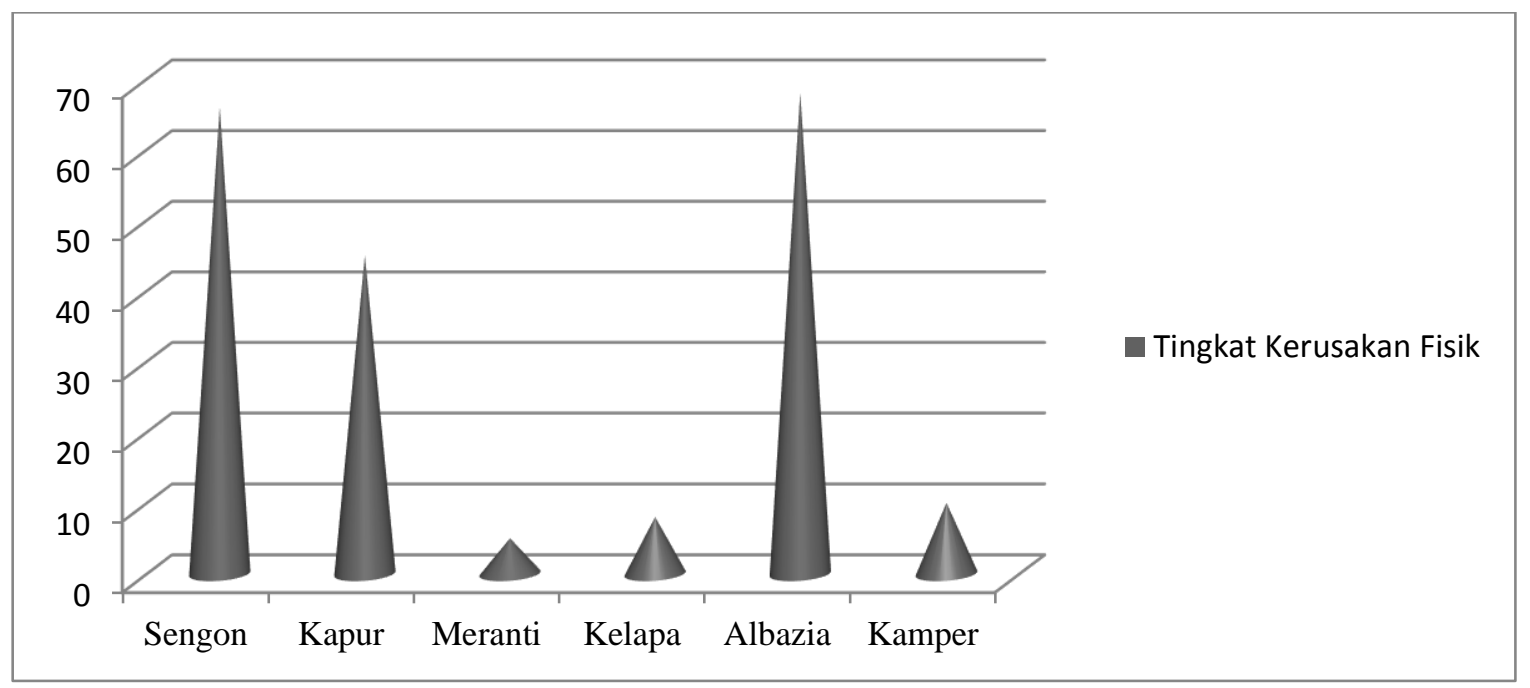

Gambar 1. Tingkat Kerusakan Kayu Olah Konstruksi pada Responden 
Potensi ekonomi kayu olah konstruksi terganggu oleh kerusakan yang terjadi akibat ketidahtahuan responden dalam mengolah keawetan kayu dengan menggunakan beberapa teknologi yang mudah dan murah. Kehilangan potensi ekonomi yang dapat merugikan responden dikarenakan harga kayu olah konstruksi yang mengalami kerusakan fisik mengalami penurunan harga dan kehilangan daya jual (tidak laku terjual). Jenis kayu yang paling rawan mengalami kerusakan fisik sebenarnya mempunyai potensi pasar paling tinggi atas permintaan konsumen. Pada Gambar 2 terurai tingkat permintaan pasar terhadap beberapa jenis kayu olah konstruksi pada responden.

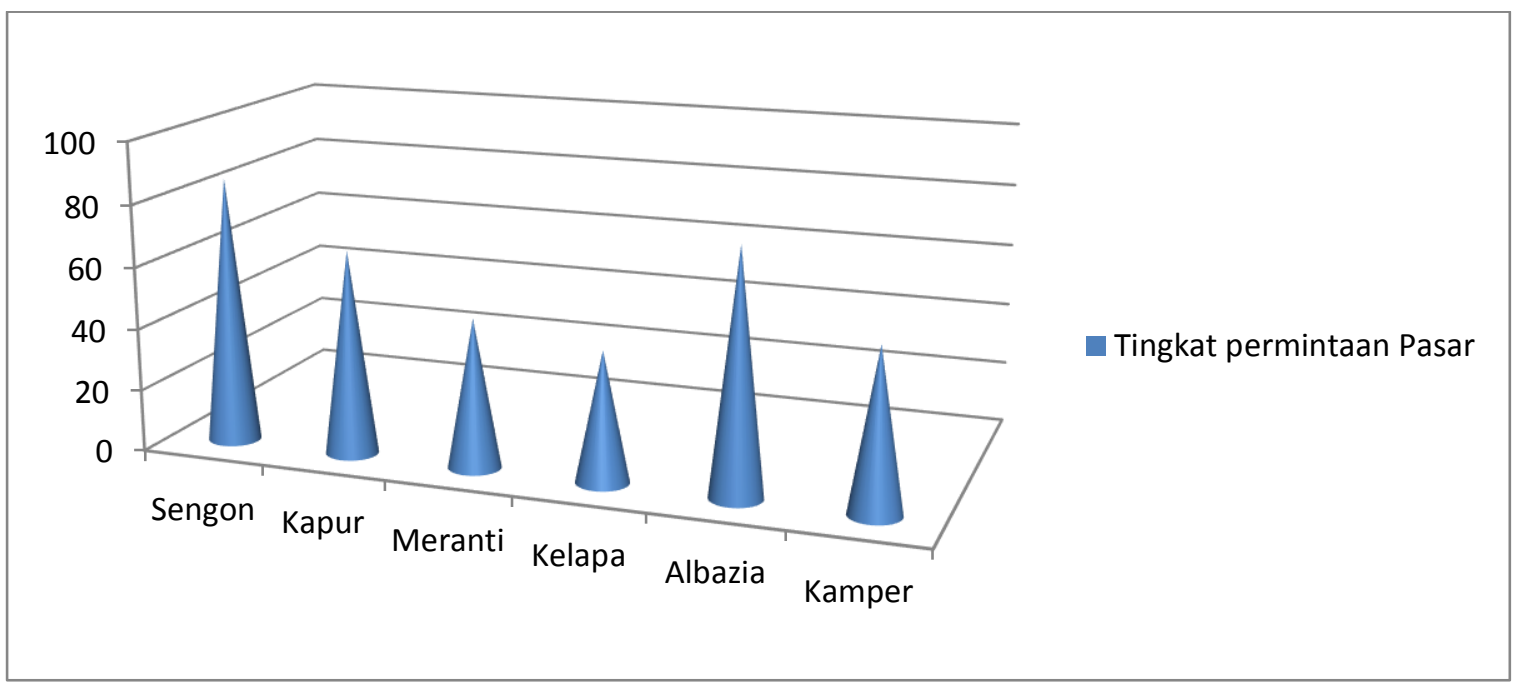

Gambar 2. Tingkat Permintaan Pasar terhadap Produk kayu Olah Konstruksi

Potensi ekonomi kayu olah konstruksi sesuai dengan nilai kemanfaatan dan fungsi untuk berbagai kepentingan. Responden hanya menyediakan beberapa jenis kayu olah konstruksi dalam bentuk papan, kayu bulat dan glondongan dalam berbagai ukuran panjang dan ketebalan. Potensi ekonomi kayu olah konstruksi berkenaan langsung dengan fungsi sebagai bahan material bagi pemenuhan ragam kebutuhan konsumen.

Kayu olah konstruksi bukan saja difungsikan nhanya untuk kepentingan bangunan rumah namun juga memiliki kemanfaatan praktis untuk kepentingan pembangunan jalan, jembatan dan lainnya. Menurut responden, mayoritas ( $>50$ persen) konsumen menggunakan kayu olah konstruksi untuk bahan material rangka 
bangunan, tiang penyangga, kusen, kuda penopang, palang, bantalan, papan dinding, papan lantai, kaso, pintu, jendela dan ventilasi. Pada Tabel 2 tertera beberapa kemanfaatan fungsional beberapa jenis kayu olah konstruksi oleh konsumen pengguna.

Tabel 2. Berbagai Bentuk Kontruksi Kayu Olah Konstruksi

\begin{tabular}{cc}
\hline No. & Konstruksi Konstruksi \\
\hline 1 & Tiang Penyangga \\
2 & Kuda Penopang \\
3 & Palang \\
4 & Bantalan \\
5 & Kaso \\
6 & Papan Dinding \\
7 & Papan Lantai \\
8 & Pintu \\
9 & Jendela \\
10 & Rangka Ventilasi \\
\hline
\end{tabular}

\section{KESIMPULAN DAN SARAN}

Manajemen teknik olah kayu konstruksi pada responden masih bersifat sederhana dan tradisional. Jenis kayu sengon, albazia dan kapur termasuk paling rawan terkena kerusakan fisik Kondisi tersebut akhirnya mengakibatkan kerugian ekonomi pada responden. Jenis kayu yang rawan terkena kerusakan fisik akibat ketiadaan teknologi pengawetan justru mempunyai nilai potensi ekonomi tinggi. Fakta sosial yang demikian perlu disadari responden sehingga segera melakukan tindakan pemanfaatan teknologi pengawetan yang mudah, murah dan ramah lingkungan. Pelaksanaan manajemen olah kayu konstruksi yang bermutu juga tidak terlepas dari fasilitas penyimpanan. Perbaikan teknik penyimpanan kayu olah konstruksi juga penting diperhatikan responden secara serius. Penyimpanan tidak dilakukan dengan cara tumpukan pada tempat yang lembab.

\section{DAFTAR PUSTAKA}

Ananta, Z., Hubeis, Musa dan Palupi, Nurheni Sri. 2007. Penerapan manajemen strategik pada industri pengolahan kayu Perusahaan XYZ di Kelurahan Bojong Kulur, Gunung Putri, Bogor. Jurnal MPI IPB. Vol. 2 (1): 24-35.

Darmawan, W., Nandika, D.; Noviyanti, E.; Irsan, A.; Dumasari, L.; Douglas, G.; Gérardin, P., 2018a. Wettability and bonding quality of exterior coatings on jabon and sengon wood surface. Journal of Coatings Technology and Research. Vol. 15 (1): 95-104.

Darmawan, W., Dodi Nandika, Britty Datin Hasna Afaf, Istie Rahayu, Dumasari Lumongga. 2018b. Radial variation in selected wood properties of Indonesian Merkusii Pine. Journal of the Korean Wood Science and Technology. Vol. 46 (4): 323-337.

Darmawan, W., Muhammad Azhari, Istie S., Rahayu, Dodi Nandika, Lumongga Dumasari, Indra Malela, Satoru Nishio. 
2018c. The chips generated during upmilling and down-milling of pine wood by helical router bits. Journal of the Indian Academy of Wood Science. Vol. 15 (20: 172-180.

Dewobroto, W., 2012. Revitalisasi kayu sebagai Bahan Material Kontruksi melalui Riset dan Pengajaran: Studi kasus di Jurusan Teknik Sipil UPH. Makalah Seminar Nasional DTP-2012, Lippo Karawaci, Tangerang, Banten,

Dumasari and Muji Rahayu, Tri Septin. 2016. Management strategy of creatice souvenir Micro enterprise for the empowerment of craftsmen peasant. Vol. 32 (1): 175-186.

Fahrizal, Rusnani dan Sudirman Muin. 2016. Analisa Biaya dan Pendapatan Industri Pengolahan Kayu di Kabupaten Kubu Raya. Jurnal Lestari Hutan. Vol. 4 (4): 643 - 648 . 